\title{
MODELING OF THE ARAL AND CASPIAN SEAS DRYING OUT INFLUENCE TO CLIMATE AND ENVIRONMENTAL CHANGES
}

Slobodan B. Marković, Albert Ruman, Milivoj B. Gavrilov, Thomas Stevens, Matija Zorn, Blaž Komac, Drago Perko

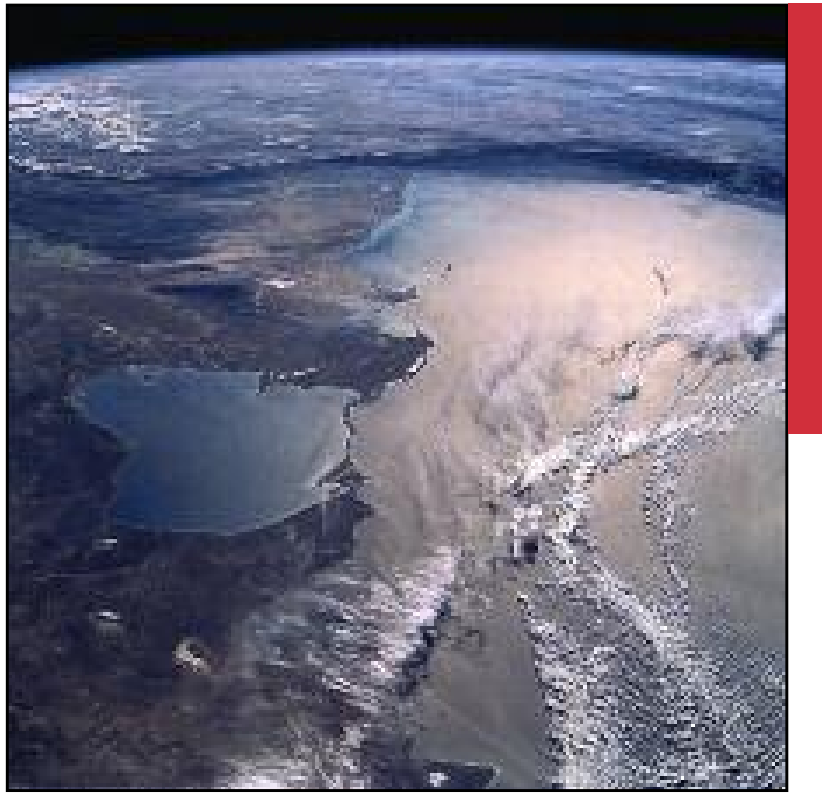

The Caspian sea (Credit: NASA). 


\title{
Modelling of the Aral and Caspian seas drying out influence to climate and environmental changes
}

DOI: http://dx.doi.org/10.3986/AGS54304

UDC: $911.2: 551.588(5-191.2)$

COBISS: 1.01

\begin{abstract}
The complete drying out of the Aral and Caspian seas, as isolated continental water bodies, and their potential impact on the climate and environment is examined with numerical simulations. Simulations use the atmospheric general circulation model (ECHAM5) as well as the hydrological discharge (HD) model of the Max-Planck-Institut für Meteorologie. The dry out is represented by replacing the water surfaces in both of the seas with land surfaces. New land surface elevation is lower, but not lover than $50 \mathrm{~m}$ from the present mean sea level. Other parameters in the model remain unchanged. The initial meteorological data is real; starting with January 1, 1989 and lasting until December 31, 1991. The final results were analyzed only for the second, as the first year of simulation was used for the model spinning up.

The drying out of both seas leads to an increase in land surface and average monthly air temperature during the summer, and a decrease of land surface and average monthly air temperature during the winter, above the Caspian Sea. The greatest difference in temperature between dry and not dry cases have the same values, about $7-8^{\circ} \mathrm{C}$ in both seasons, while daily extremes of temperature are much more pronounced. In the wider local/regional area, close to both seas, drying out leads to a difference in average annual temperatures by about $1{ }^{\circ} \mathrm{C}$. On a global scale, the average annual temperature remains unchanged and the configuration of the isotherms remain unchanged, except for over some of the continents. In winter, Central Asia becomes cooler, while over Australia, southern Africa, and South America, it becomes slightly less warm. Furthermore, a new heat island occurs in western Sahara during summer.
\end{abstract}

KEY WORDS: Caspian Sea, Aral Sea, drying out, numerical simulation, air temperature, climate change

The article was submitted for publication on April 3, 2013.

\section{ADDRESSES:}

Slobodan B. Marković, Ph. D.

Chair of Physical Geography, Department of Geography, Tourism and Hotel Management

Faculty of Sciences, University of Novi Sad

Trg Dositeja Obradovića 3, RS - 21000 Novi Sad, Serbia

E-mail: slobodan.markovic@dgt.uns.ac.rs

\author{
Albert Ruman, M. Sc. \\ Republic Hydrometeorological Service \\ Kneza Višeslava 66, RS - 11000 Beograd, Serbia \\ E-mail: albert.ruman@hidmet.gov.rs
}

Milivoj B. Gavrilov, Ph. D.

Chair of Physical Geography, Department of Geography, Tourism and Hotel Management

Faculty of Sciences, University of Novi Sad

Trg Dositeja Obradovića 3, RS - 21000 Novi Sad, Serbia

E-mail:milivoj.gavrilov@yahoo.com

Thomas Stevens, Ph. D.

Centre for Quaternary Research, Department of Geography

Royal Holloway, University of London

Egham, Surrey TW20 0EX, UK

E-mail: Thomas.Stevens@rhul.ac.uk 


\section{Matija Zorn, Ph. D.}

Anton Melik Geographical Institute

Research Centre of the Slovenian Academy of Sciences and Arts

Gosposka ulica 13, SI - 1000 Ljubljana, Slovenia

E-mail: matija.zorn@zrc-sazu.si

\section{Blaž Komac, Ph. D.}

Anton Melik Geographical Institute

Research Centre of the Slovenian Academy of Sciences and Arts

Gosposka ulica 13, SI - 1000 Ljubljana, Slovenia

E-mail: blaz.komac@zrc-sazu.si

\section{Drago Perko, Ph. D.}

Anton Melik Geographical Institute

Research Centre of the Slovenian Academy of Sciences and Arts

Gosposka ulica 13, SI - 1000 Ljubljana, Slovenia

E-mail: drago@zrc-sazu.si 


\section{Introduction}

Since the beginning of Earth's history, climate has varied (Goosse et al. 2013). Its climate system is affected by many factors that can be classified into three major groups:

- astronomical factors, such as solar or Earth orbital variability;

- natural landscape factors, such as spatial distribution of land and sea, configuration and type of land surface, vegetation cover and

- anthropogenic factors, such as atmospheric composition and land use.

The latter influences climate only in recent centuries (e.g. Dahan 2010).

The study of current/recent climate change is focused on two main themes:

- the net overall climate change and

- constraining the relative influences of natural versus anthropogenic influences (Hansen and Sato 2012).

This paper examines the potential impact of the drying out of the Aral and Caspian seas on local, regional, and global climate and environment. In the case of the Aral Sea's recent progressive drying out process is mostly triggered only by anthropogenic factors. Current human influence on the hydrological regimes in catchments of the Aral Sea results in its reduced surface and volume (Peneva et al. 2004; Toman 2013), leading to its immanent final disappearance. In the case of Caspian Sea the human influence has not been so severe, although the sea level drop caused by big contractions on Volga River are reported since the 1950s (Vrišer 1953). Thus the disappearance of the Caspian Sea can be significantly accelerated in the case of major inflow decrease of water from the main tributaries, the Volga and Ural rivers. On the other hand, also natural influence on the hydrological regimes in the catchment of the Caspian Sea has been observed. The Caspian Sea is subject to large variations in the amount of water and water surface, as it was during the Late Pleistocene and postglacial periods (Kislov et al. 2012). Without going into the details of all of these processes, our study introduces a presumption that the drying out of the Aral and Caspian seas has happened in the last decades. The influence of drying out on air temperature will be considered. Beside the impact on the climate, the drying out of the inland seas would impact the environment and ultimately the human society.

It is a widely accepted view that the roots of today's civilization are linked to ancient human societies that existed in the valleys of major rivers, such as the Nile in Africa, the Tigris and Euphrates rivers in the Middle East, the Indus in South Asia, and the Yangtze and Yellow rivers in China. Many civilizations took advantage of natural flooding of rivers for agricultural development, and later developed irrigation and flooding control to further enhance farming conditions (Diamond 2005). Water management should be planned, including digging of channels to organize work in the fields, keeping accurate records, taking care of security, implementing control, synchronizing decisions and transmitting orders. Economy was subordinated to the very complex interface between human organization and management. Over time, these teams ensured the emergence and development of civilizations in the river valleys. Civilizations based on good water management survived the longest of all in the past, and are sometimes referred to as »hydraulic civilizations « (Gavrilov 2005). Multi millennial experience in water management has mainly brought blessings. Until recently, people did not notice the consequences of bad management.

\subsection{Aral Sea}

The Aral Sea is lying between Kazakhstan in the north and Uzbekistan in the south. It is a completely enclosed basin with a large inland catchment area. Most of the surrounding land is desert and almost all water entering the basin comes from two major rivers: Amu Darya and Sir Darya (Peneva et al. 2004; Toman 2013). The name of the Aral Sea roughly translates from old Turkish as »Sea of Islands", referring to the more than 1,534 islands that once dotted its waters. Previously it was the fourth largest lake in the world with an area of $68,000 \mathrm{~km}^{2}$ (Figure 1). The Aral Sea has been steadily shrinking since the 1960s after the Amu Darya and Sir Darya Rivers were diverted by Soviet irrigation projects. By 2007, it had declined to $10 \%$ of its original size, splitting into four lakes: the North Aral Sea, the eastern and western basins of the once far larger South Aral Sea, and one smaller lake between the North and South Aral Sea (Micklin and Aladin 2008). By 2009, the southeastern lake had disappeared and the southwestern lake retreated into a smaller water bodies at the far west of the former southern sea (Singh et al. 2012; Figure 2). 
The shrinking of the Aral Sea has been called one of the planet's worst environmental disasters. The region's once prosperous fishing industry has been essentially destroyed, bringing unemployment and economic hardship. The Aral Sea region is also heavily polluted, with resulting serious public health problems. The retreat of the sea has reportedly also caused local climate change, with summers becoming hotter and drier, and the winters becoming colder and longer (Micklin 2007).

\subsection{Caspian Sea}

The Caspian Sea is situated in a semi-arid area between southern Russia, Kazakhstan, Turkmenistan, Iran and Azerbaijan $\left(36^{\circ}-47^{\circ} \mathrm{N}, 47^{\circ}-54^{\circ} \mathrm{E}\right)$ and currently lies $27 \mathrm{~m}$ below sea level. It is the world's largest inland body of water without a connection to the world oceans, with a surface area of $390,000 \mathrm{~km}^{2}$ and volume of $66,100 \mathrm{~km}^{3}$ (Figure 3 ). It is a reservoir of brackish waters, highly sensitive to climate changes. It has large catchment area of approximately 3.5 million $\mathrm{km}^{2}$ (Arpe and Leroy 2007; Arpe et al. 2012). The salinity of the Caspian Sea varies from the north to the south from 1.0 to $13.5 \%$. This difference is most marked in the north due to the freshwater supplied by the Volga River. In other areas, average water salinity is $12.5 \%$ (Dumont 1998). The Caspian Sea is divided into three basins but differing in depth and volume: the south (water depth up to $<1020 \mathrm{~m})$, middle $(<900 \mathrm{~m})$ and north $(<15 \mathrm{~m})$ basins, which represent two-thirds, one-third and $1 \%$ of the total volume of water, respectively. The Caspian Sea was formed in the Pliocene, about 3 million years ago, after its separation from the Black and Pannonian seas. From that time, due to specific geomorphological conditions, it has experienced numerous transgressions and regressions with water level fluctuations of several tens of meters (Varuschenko et al. 1987), causing important changes in its shoreline, particulary in the north (Tudryn et al. 2013). The current environmental changes experienced in the area, especially the negative water budget in the northern and eastern shallow parts of Caspian Sea, indicate serious consequences.

\section{The model}

The atmospheric general circulation model ECHAM5 (Roeckner et al. 2003) was used for simulations presented in this study. This fifth-generation atmospheric general circulation model developed at the Max-Planck-Institut für Meteorologie (MPIM) in Germany is the most recent version in a series of ECHAM model versions evolving originally from the spectral weather prediction model of the European Centre for Medium Range Weather Forecasts (ECMWF), (Simmons et al. 1989).

The ECHAM5 is well designed for climatological studies (Roeckner et al. 2004), because there are many good solutions in numerics and physics of the model. It is important to note that a hydrological discharge model (Hagemann and Dümenil 1996; 1998; Hagemann et al. 2006), developed at MPIM, is included in the ECHAM5 model. Also, ECHAM5 has been used for research similar to these (e.g. Kislov et al. 2012).

The horizontal resolution (spectral transaction) of the ECHAM5 model is T42 $(128 \times 64$ grid point or $221 \times 221 \mathrm{~km}$ on latitude $45^{\circ}$ ), the model had 19 vertical layers and a time step of $1800 \mathrm{~s}$. Other parameters of model were standardized and/or adapted to the capacities of computer used.

\section{Geographical areas}

The model used two types of global geographical areas. The first is the original geographical area, as used in the basic version model ECHAM5. This area is marked with G1. Part of G1 around the Aral and Caspian seas labelled as area A1, $\left(32.1^{\circ}-60.0^{\circ} \mathrm{N}, 39.3^{\circ}-67.5^{\circ} \mathrm{E}\right)$ is shown in Figure 5.

The area A1 shows a distinct geographic configuration of land and sea on the surface and state borders before the collapse of the Soviet Union (the green lines) all around the Aral and Caspian seas. Also, A1 shows the values of the lake mask (LM) in equidistant grid points. Lake mask is a special value in ECHAM5, which is the ratio of areas of land and water per a box in the grid points, but only on the mainland (Hagemann 2002). LM takes values between 0 and 1, as markers for land $100 \%$ and for water $100 \%$, all on the land, respectively. It should be noted that there is no value LM over the oceans and seas.

Second type of global geographical area is the modified geographical area, marked as G2. Part of G2 around the Aral and Caspian seas, previously marked as A1, is shown in Figure 6. 


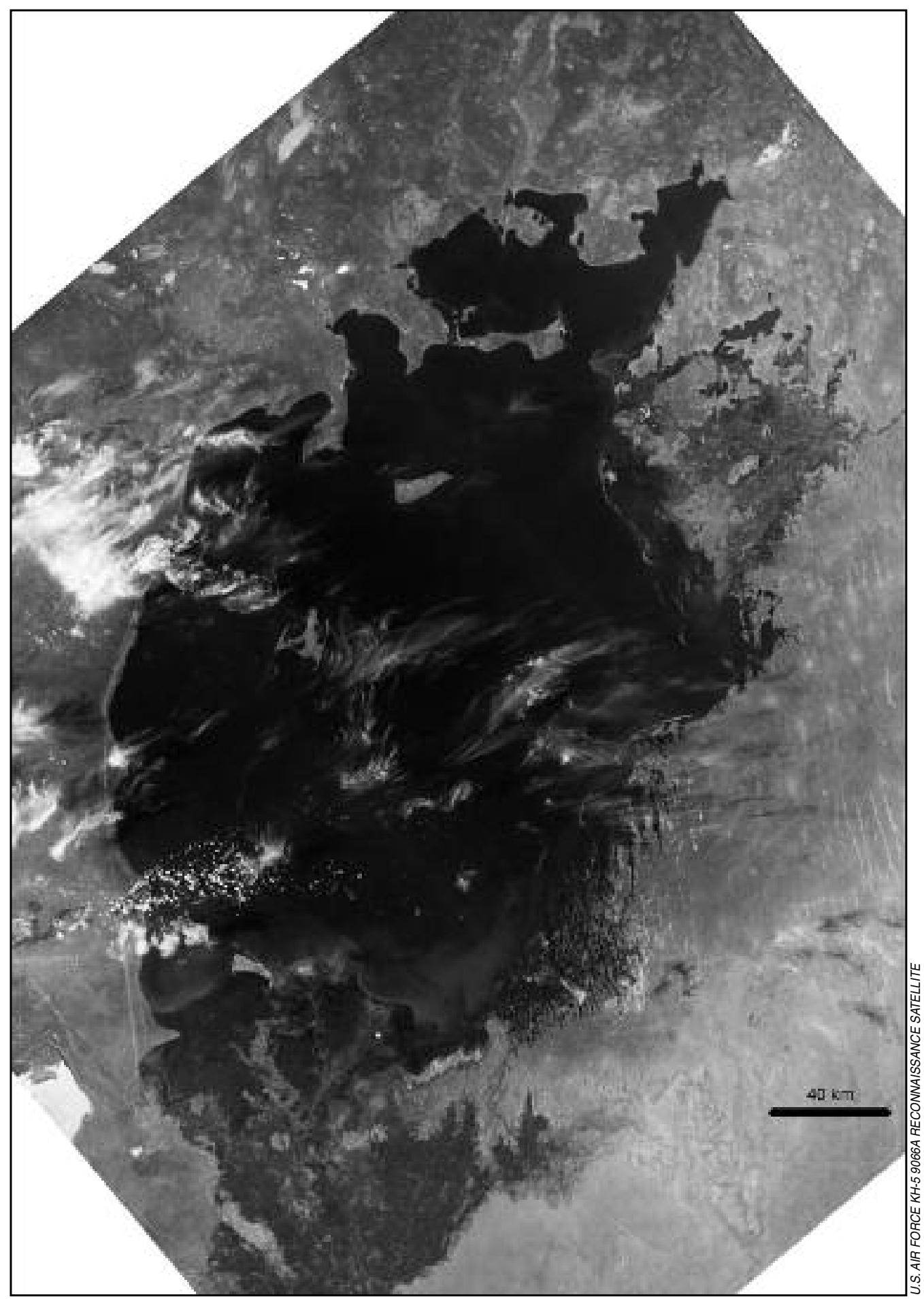

Figure 1: The Aral Sea in the year 1964 (Credit: NASA Earth Observatory). 


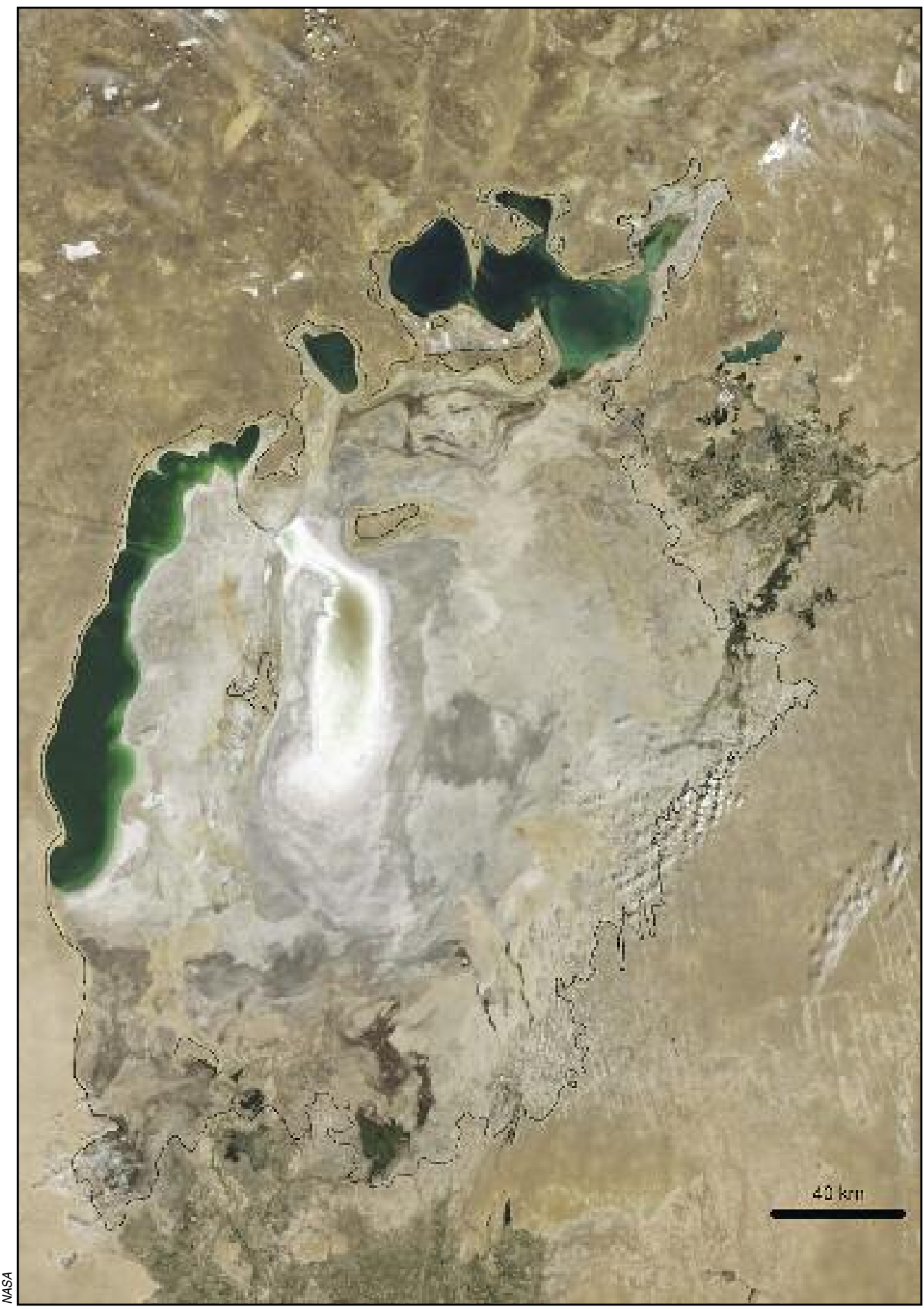

Figure 2: The Aral Sea in the year 2009 (the black line shows the extend of the Aral Sea in the year 1960; Credit: NASA Earth Observatory). 


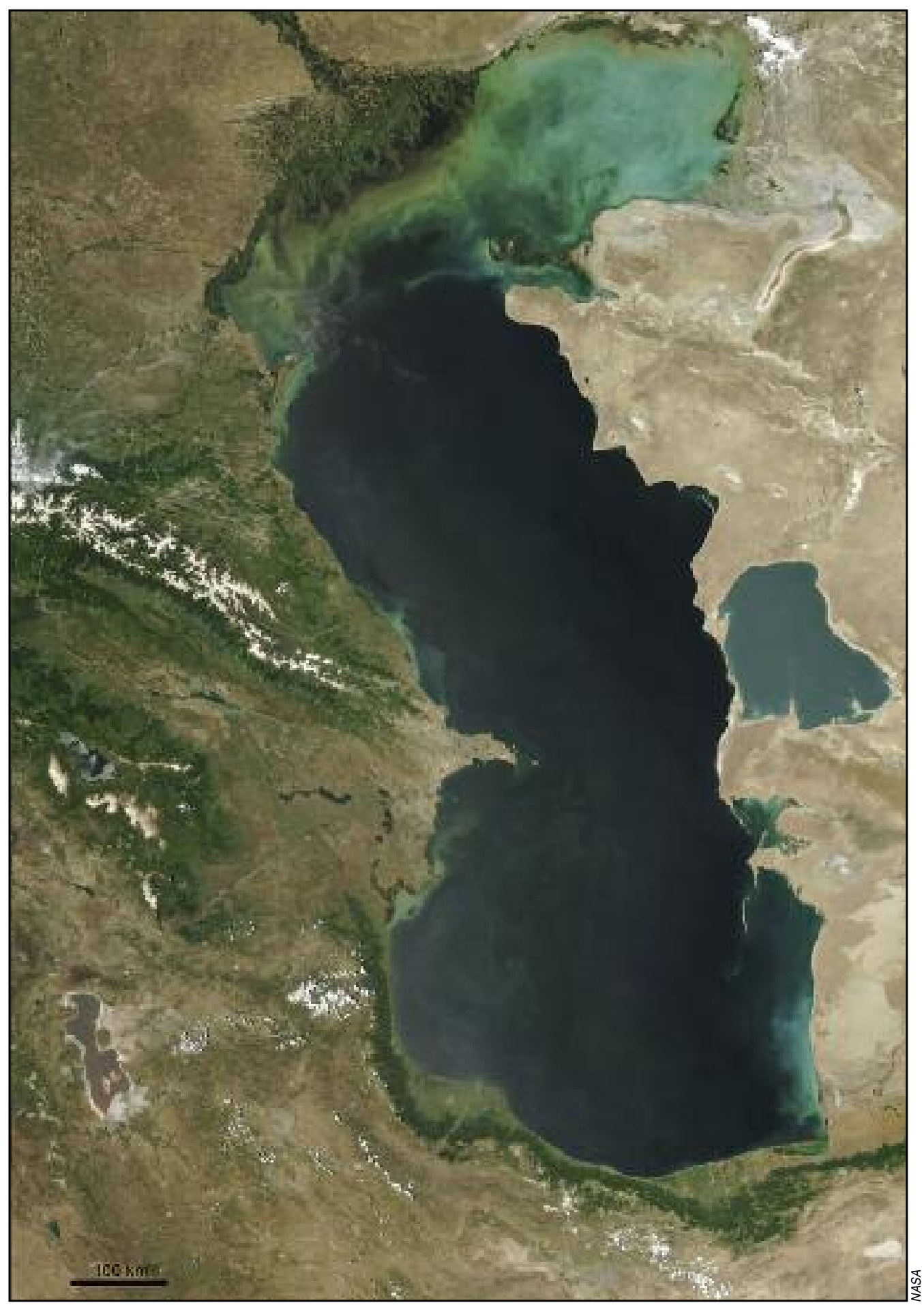

Figure 3: The Caspian Sea is the world's largest inland body of water (Credit: NASA Earth Observatory). 


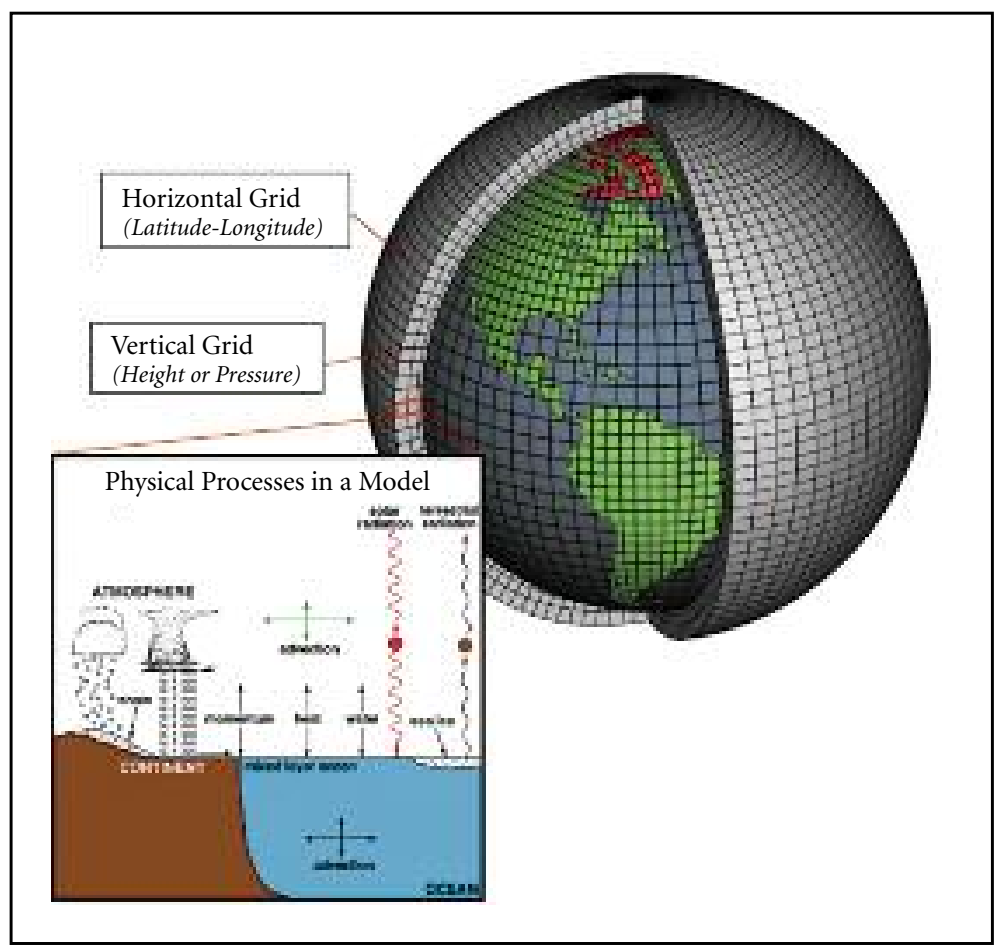

Figure 4: Schematic representation of the main components of the numerical model of the atmosphere (Internet 1). Besides horizontal (latitude-longitude) grid and vertical (height or pressure) grids in spherical geometry (Earth globe), can be seen the most important physical processes in the atmosphere, continents and oceans, such as solar and terrestrial radiation, advection, momentums, heat, water, clouds, precipitations, sea ice and mixed layer ocean. All the above mentioned components and processes are connected to natural laws, which are described by mathematical equations, whose are solutions obtain on the computers by using the initial data of the atmosphere, oceans and continents, and finally after a lot of calculations the output data are obtain as results of the model (Gavrilov etal. 2011).

G2 is identical to G1, but has the new values of the lake mask (LM) in a rectangular frame, marked as A2, $\left(34.8^{\circ}-48.8^{\circ} \mathrm{N}, 45.0^{\circ}-64.7^{\circ} \mathrm{E}\right)$ that is embedded in $\mathrm{A} 1$. The area $\mathrm{A} 2$ was developed for the purposes of numerical simulation of the drying out of the Aral and Caspian seas. The drying out is achieved by putting 0 in all grid points in A2, making both seas disappear. Besides these, other changes in the model have not been carried out.

\section{Data}

In all cases the same initial set of global data from 1 January 1989 was used (ERA40 Reanalyse Data 01/01/1989). For this data an initialization procedure (e.g. Wiin-Nielsen 1978) was applied that adjusted the data to each other and on the normal/actual geographical area (G1). Therefore, the initial data had to be adjusted to the changing (modified) geographical area (G2).

\section{Simulations}

Only one numerical simulation was run for each of the two types of geographical areas: G1 and G2. It is clear that when geographical area G1 is used, both the Aral and Caspian seas are in the model. In contrast when geographical area G2 is used, both seas were omitted from the model. Both simulations were carried out for two years until 31 December 1991. The first year of simulation was used for the model 


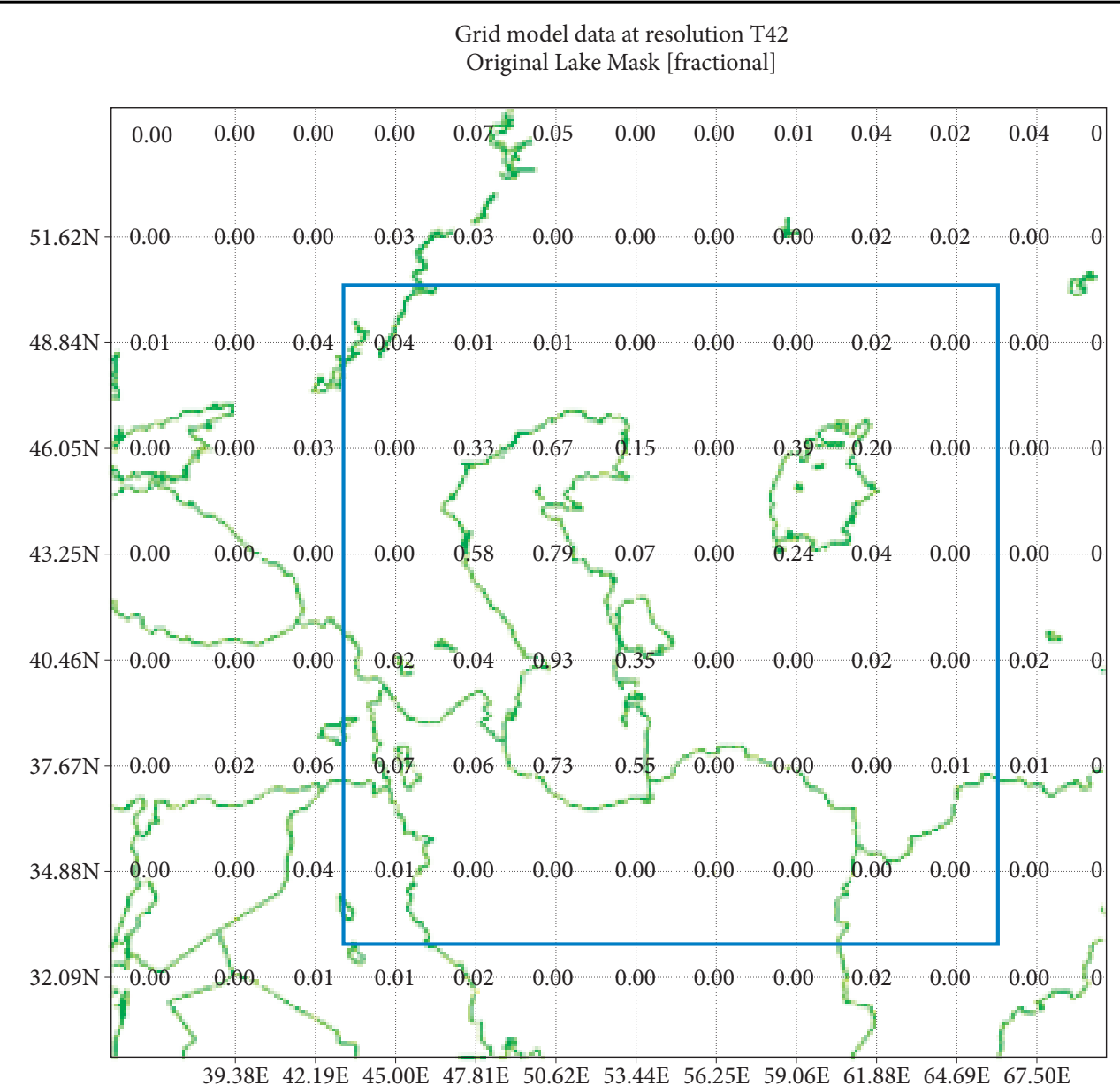

Figure 5: Area A1 as part of normal global geographical area (G1) in model ECHAM5 around the Aral and Caspian seas, showing the original lake mask (LM).

spinning up, while data from the second year was used for analysis. It is considered that this simulation of the entire climatological season is sufficient for adjustment to new conditions.

\section{Results and analysis}

All output data models are produced for both simulations with original (G1), and modified (G2) geographical areas. For this purpose, only air temperature is considered as the main climatic parameter. The temperature will be displayed in two cases; as a local/regional and as a global and continental indicator of climate change.

\subsection{Local and regional impact}

To investigate local/regional changes in the vicinity of both the Aral and Caspian seas, two parameters were used. One parameter is the average monthly temperature for January and August at two levels (at the surface and $100 \mathrm{~m}$ above it) along the meridian of longitude $50.625 \mathrm{E}$. 
Grid model data at resolution T42

New lake mask [fractional]

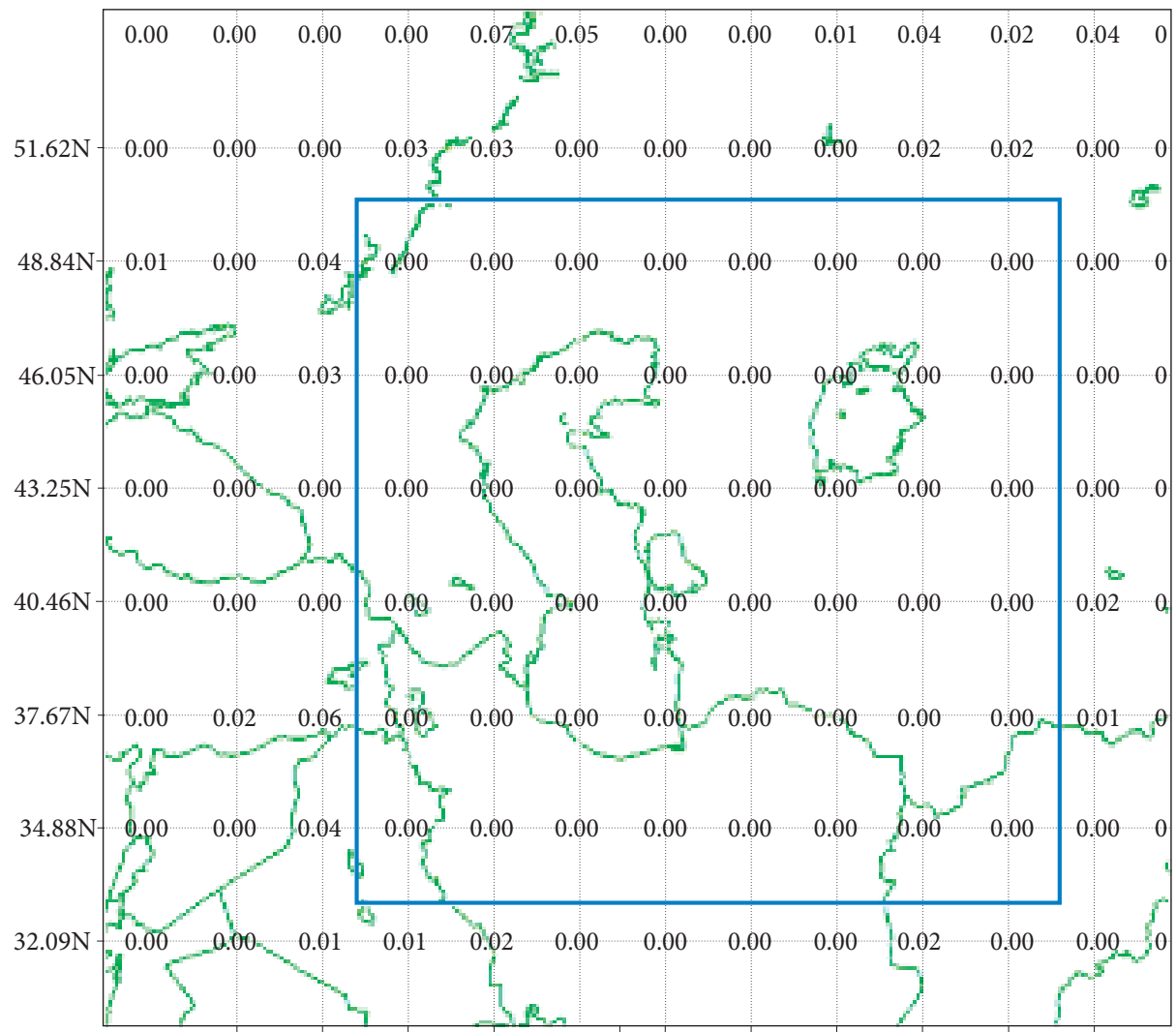

39.38E $42.19 \mathrm{E} \quad 45.00 \mathrm{E} \quad 47.81 \mathrm{E} \quad 50.62 \mathrm{E} 53.44 \mathrm{E} 56.25 \mathrm{E} \quad 59.06 \mathrm{E} \quad 61.88 \mathrm{E} \quad 64.69 \mathrm{E} \quad 67.50 \mathrm{E}$

Figure 6: Area A1 as part of modified global geographical area (G2) around the Aral and Caspian seas, showing the new lake mask (LM) in the rectangular frame labelled as A2.

The average monthly temperature for January and August at both levels can be seen in Figures 7-10, respectively. Green indicates the temperature distribution in the original geographic area (G1), and red is the temperature in the modified geographic area (G2).

As shown in Figures 7 and 8, draining the Aral and Caspian seas leads to a decrease in January temperature at both levels along the longitudinal direction $(50.625 \mathrm{E})$. The greatest difference in temperature is about $7-8^{\circ} \mathrm{C}$ around the centre line, and north and south of the centre line the difference in temperature monotonically decreases to about $1-2^{\circ} \mathrm{C}$ in both cases. The lines are approximately matched at both levels. As can be seen, draining of the lakes reduces average monthly temperature during winter for about $8^{\circ} \mathrm{C}$, while the daily extremes of temperature drop may be much higher.

As shown in Figures 9 and 10, draining of the Aral and Caspian seas leads to an increase in temperature during August at both altitude levels along the longitudinal direction $(50.625 \mathrm{E})$. The greatest difference in surface temperature is about $7-8^{\circ} \mathrm{C}$ in the regions from 37.67 to $43.25^{\circ} \mathrm{N}$. The greatest differences in temperature are similar in height, with the exception of $40.46^{\circ} \mathrm{N}$, where the difference is less than $2{ }^{\circ} \mathrm{C}$. At the southern and northern ends of the longitudinal direction (50.625E), temperature differences disappear. Lines are approximately matched at both levels. Draining both of the lakes increases average monthly temperature during the summer for about $8^{\circ} \mathrm{C}$, while the daily extremes of temperature rise may be much greater. 


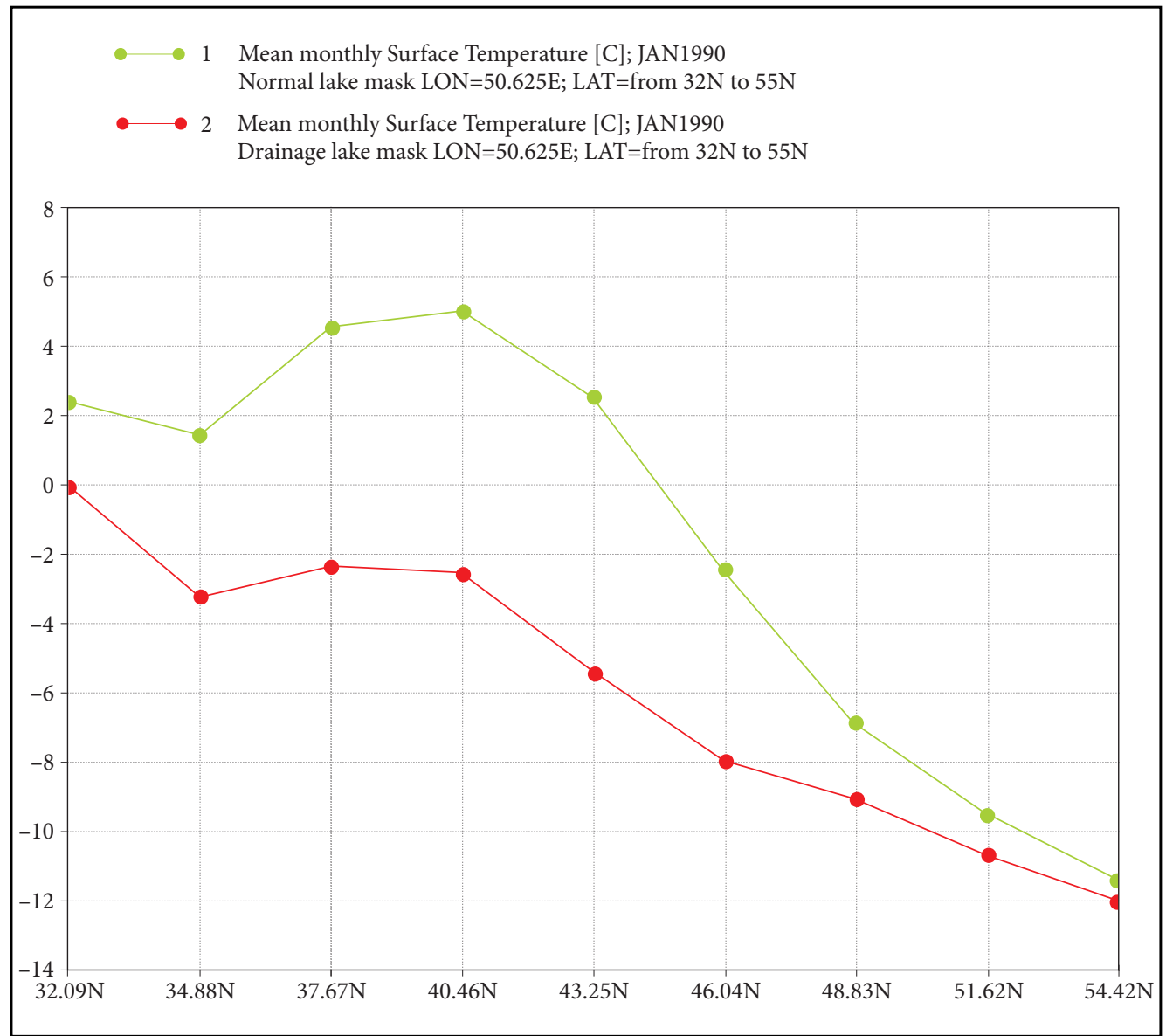

Figure 7: Surface average monthly temperature for January.

Another parameter of change is the average surface annual temperature in A2, as a local indicator, and in A1, as a regional indicator for both simulations. The values of these temperatures can be seen in Table 1.

Table 1: Average annual surface temperature in areas A1 and A2 for simulations G1 and G2.

\begin{tabular}{lcc}
\hline & $\mathrm{G} 1$ & $\mathrm{G} 2$ \\
\hline $\mathrm{A} 2$ & $14.73^{\circ} \mathrm{C}$ & $13.82^{\circ} \mathrm{C}$ \\
$\mathrm{A} 1$ & $11.67^{\circ} \mathrm{C}$ & $10.51^{\circ} \mathrm{C}$ \\
\hline
\end{tabular}

As shown in Table 1, draining the Aral and Caspian seas leads to an overall decrease in average annual surface temperature in both areas. Since the difference in temperature is slightly greater in area A1, it is considered that draining both lakes have a greater impact on the local rather than regional climate.

\subsection{Potential global impact}

In the second case, as global and continental indicator of climate change, we used two parameters. One parameter of change was the average annual global surface temperature. This temperature was the same, 


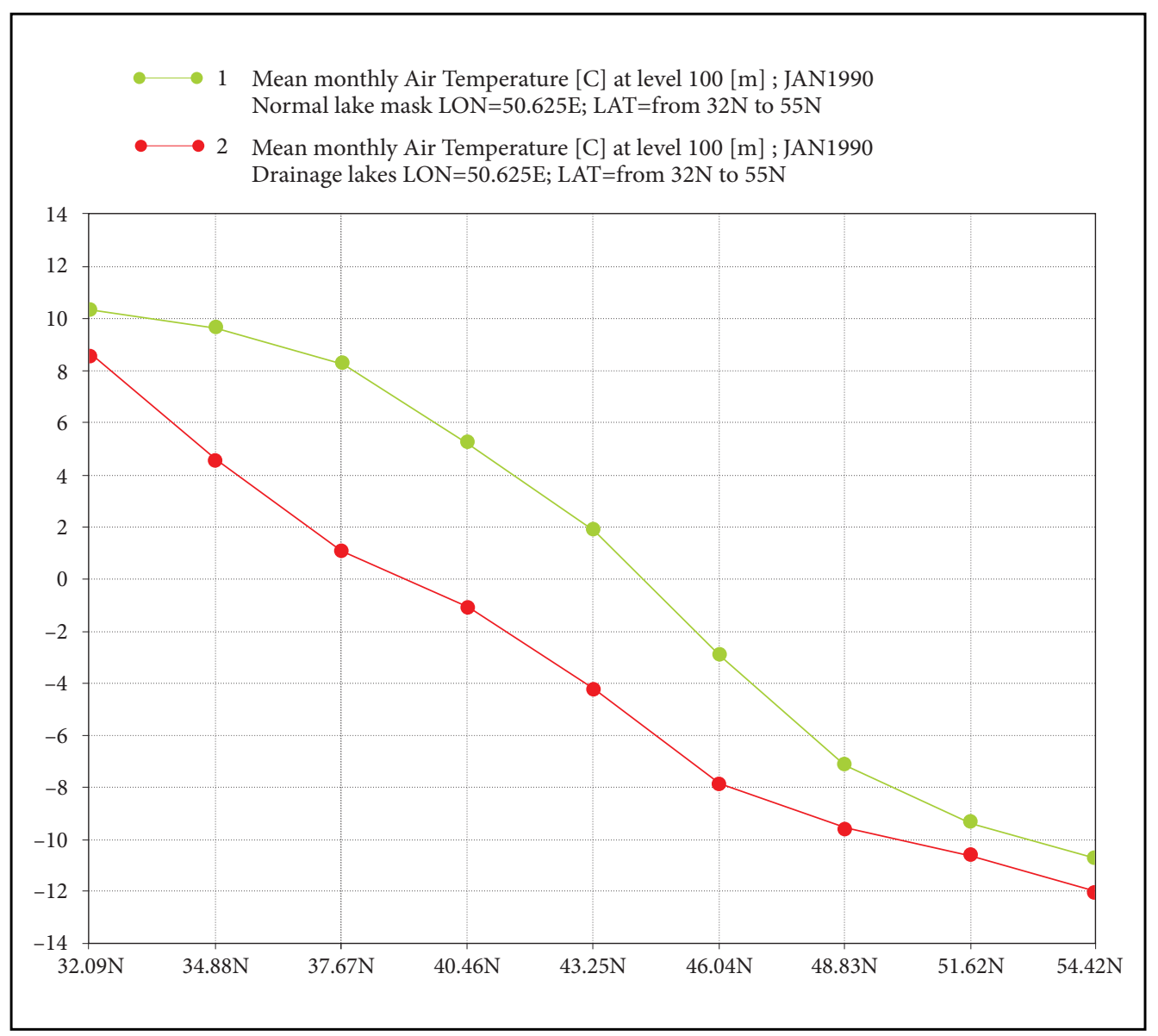

Figure 8: $100 \mathrm{~m}$ above average monthly temperature for January.

$15.1^{\circ} \mathrm{C}$, for both simulations. As such, according to the model, draining the Aral and Caspian seas had no effect on the average annual global surface temperature. However, another set of parameters of change are the global distribution of average monthly surface temperatures for particular months, in this case January and August. These temperatures are shown on maps in Figures 11-14.

As shown in Figures 11 and 12, draining the Aral and Caspian seas lead to significant differences in temperature distribution over Asia during January. In the case of G1, the zero isotherm meanders through the middle of area $\mathrm{A} 1$, while in the case of $\mathrm{G} 2$ the zero isotherm has a zonal slope and extends to the south, almost to $30^{\circ} \mathrm{N}$. Also, in the case of $\mathrm{G} 1$, the $-20^{\circ} \mathrm{C}$ isotherm is located in NE Asia to NW-SE direction, while in the case of G2 this isotherm penetrates the centre of the continent. It can be concluded that the removal of both seas lead to cooling of Asia during winter. By contrast, the configuration of isotherms in other parts of the world remains nearly unchanged. It may be noted that the warmest areas in Australia, southern Africa and South America are less pronounced in G2 than in G1.

As shown in Figures 13 and 14, draining the Aral and Caspian seas does not significantly change the configuration of August isotherms, but it does change the distribution of the hottest areas in Asia and Africa. In the case of the G2 simulation, on the locations of the Aral and Caspian seas is becoming warmer. Also, in addition to the three areas of extreme high temperatures in Asia (two in the Arabian Peninsula and third in Kashmir), there are additional areas of extreme temperatures in the western Sahara. Another significant trend is the cooling of the Tibetan plateau to a greater extent than the surrounding regions. 
- 1 Mean monthly Surface Temperature [C]; AUG 1990 Normal lake mask $\mathrm{LON}=50.625 \mathrm{E}$; $\mathrm{LAT}=$ from $32 \mathrm{~N}$ to $55 \mathrm{~N}$

- 2 Mean monthly Surface Temperature [C]; AUG 1990 Drainage lake mask $\mathrm{LON}=50.625 \mathrm{E}$; $\mathrm{LAT}=$ from $32 \mathrm{~N}$ to $55 \mathrm{~N}$

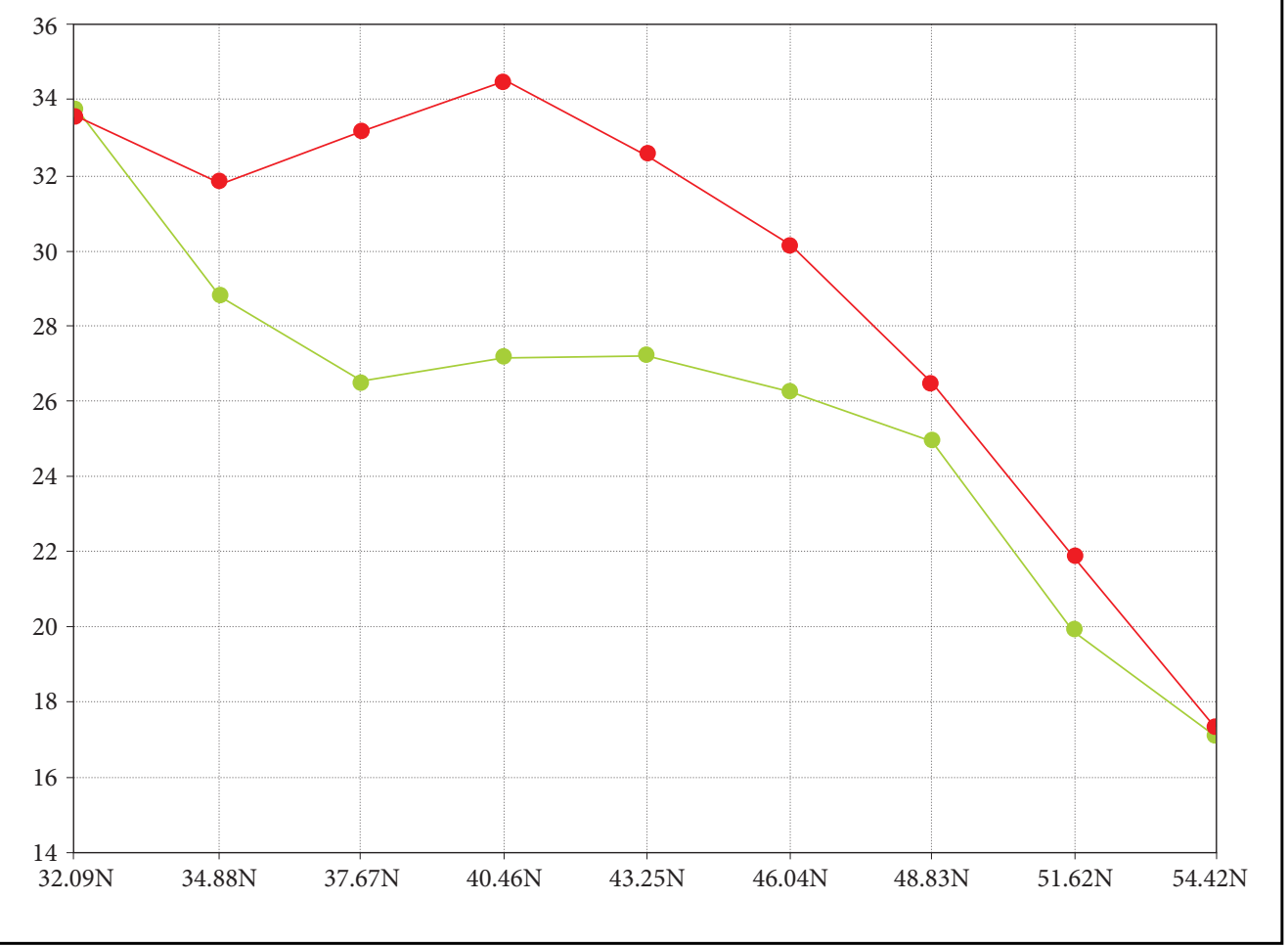

Figure 9: Surface average monthly temperature for August.

\section{Discussion and conclusion}

We evaluated climate and environmental changes in the case of a complete drying out of the two large inland seas of the Aral and Caspian seas, located in arid and semiarid continental areas. This kind of scenarios are quite plausible, as the Aral Sea is already almost completely dried up, while shallow parts of the Caspian Sea are being transformed into terrestrial ecosystems. As such, it is important to model the effects on both local and regional/global conditions.

The modelling results using the ECHAM5 model are quite dramatic. Comparing the temperature changes it was found that the drying out of both the Aral and Caspian seas leads to an increase in summer and decrease in winter average monthly temperature by the similar amount, from about $7-8^{\circ} \mathrm{C}$, while the daily extremes of temperature may be even more pronounced. In the wider regional zone, close to both seas, the average annual temperature is reduced by about $1^{\circ} \mathrm{C}$. However, at the global scale, average annual temperature remains unchanged, while the general configuration of the isotherms remains unchanged, except for some shifts over the continents.

Presented approach can also be applied to paleoclimatic research. Spatial and temporal changes of the Paratethys Basins can be regarded as a key factor responsible for Cenozoic climate changes (Ramstein et al. 1997). The results of this study demonstrate that the drying out of isolated sea basins such as the described ones can cause significant regional climatic and environmental changes. Similar was shown for the drying out 


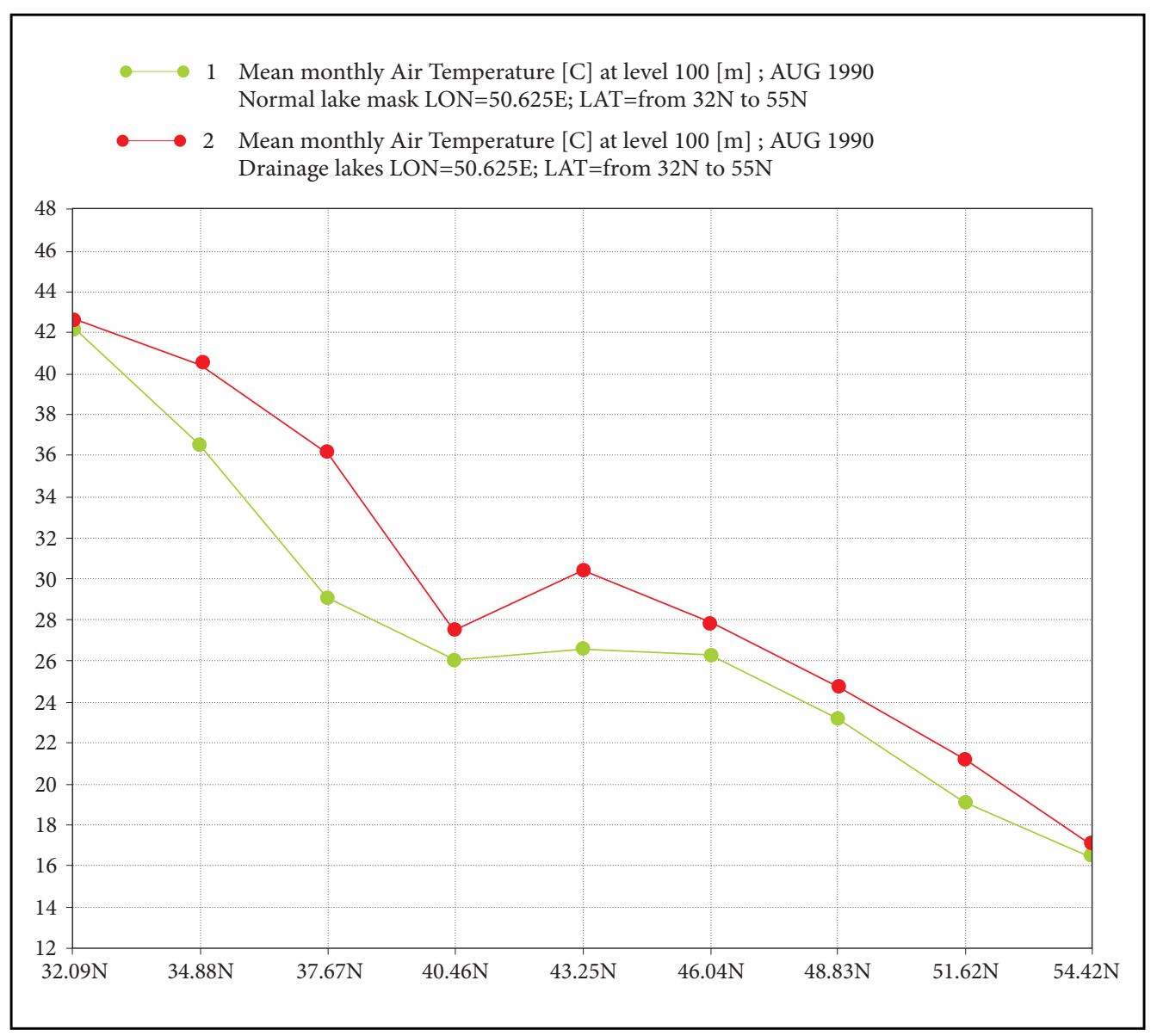

Figure 10: $100 \mathrm{~m}$ above average monthly temperature for August.

of Mediterranean Basin (Murphy et al. 2009), or drying out of Paratethys Basins, e.g. the present Pannonian Basin (Hamon et al. 2013).

\section{Acknowledgments}

This research paper is financed by Project 176020 of the Serbian Ministry of Education, Science and Technological Development and Project 114-451-2670 of Secretariat of Science and Technological Development of Vojvodina province government. The authors are grateful for the support of Slobodan Ničković and Valentina Janc.

\section{References}

Arpe, K., Leroy, S. A. G. 2007: The Caspian Sea Level forced by the atmospheric circulation, as observed and modelled. Quaternary international 173-174. DOI: http://dx.doi.org/10.1016/j.quaint.2007.03.008 Arpe, K., Leroy, S. A. G., Lahijani, H., Khan, V. 2012: Impact of the European Russia drought in 2010 on the Caspian Sea level. Hydrology and earth system science 16. DOI: http://dx.doi.org/10.5194/ hess-16-19-2012 
Forecast mean surface temperature [C] JAN 1990

Normal lake mask

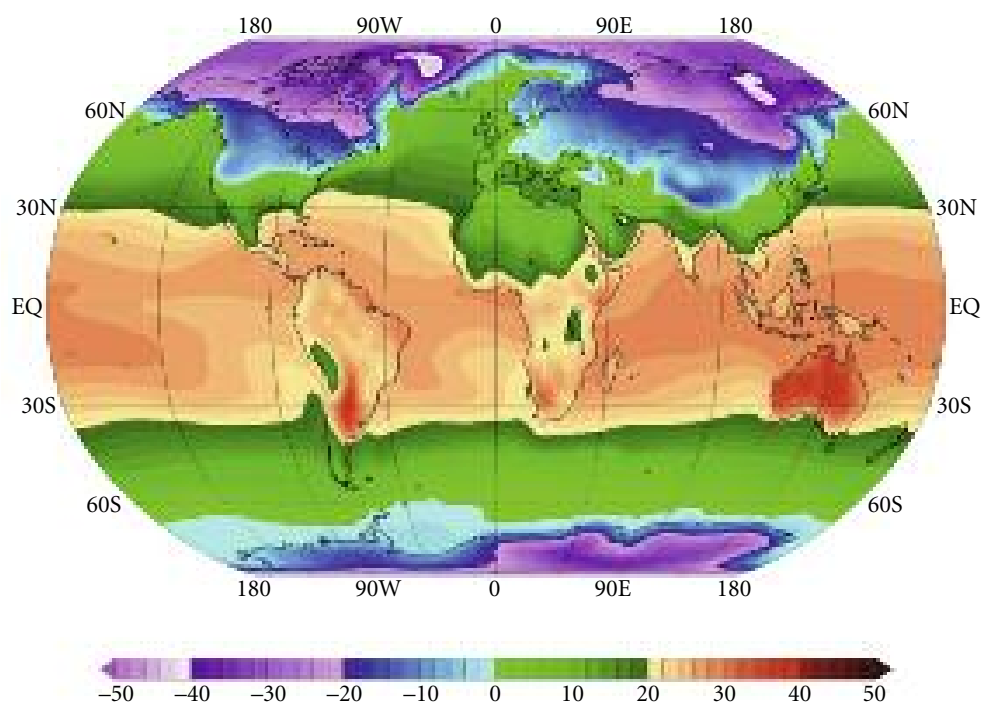

Figure 11: Global distribution of surface average January temperatures in G1.

Forecast mean surface temperature [C] JAN 1990

Drainage of the Caspian and the Aral lake

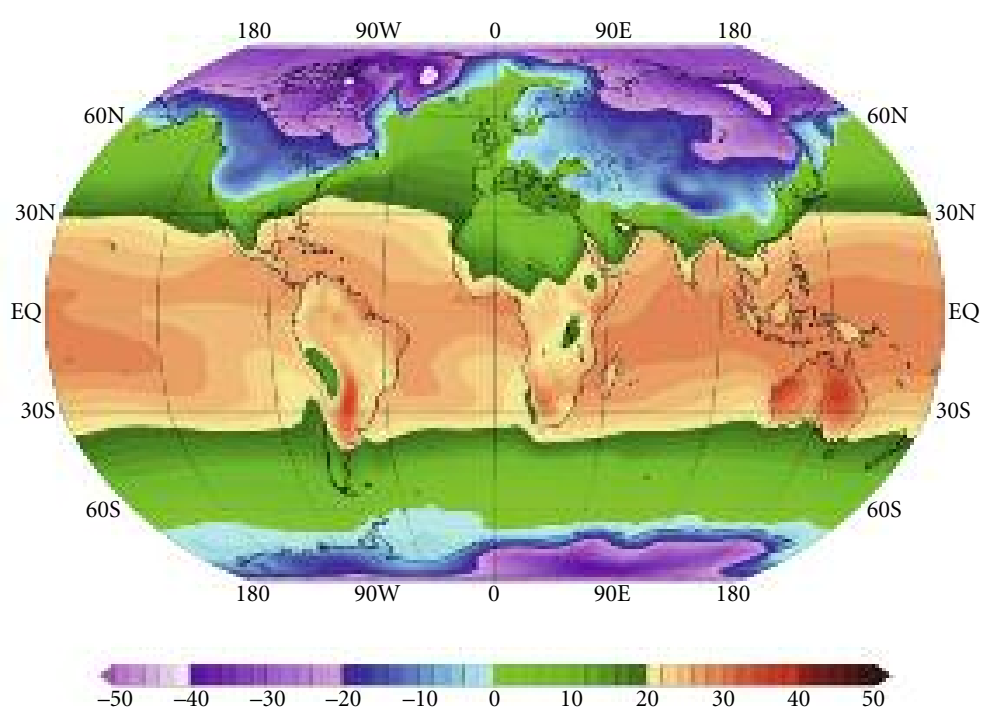

Figure 12: Global distribution of surface average January temperatures in G2. 
Forecast mean surface temperature [C] AUG 1990

Normal lake mask
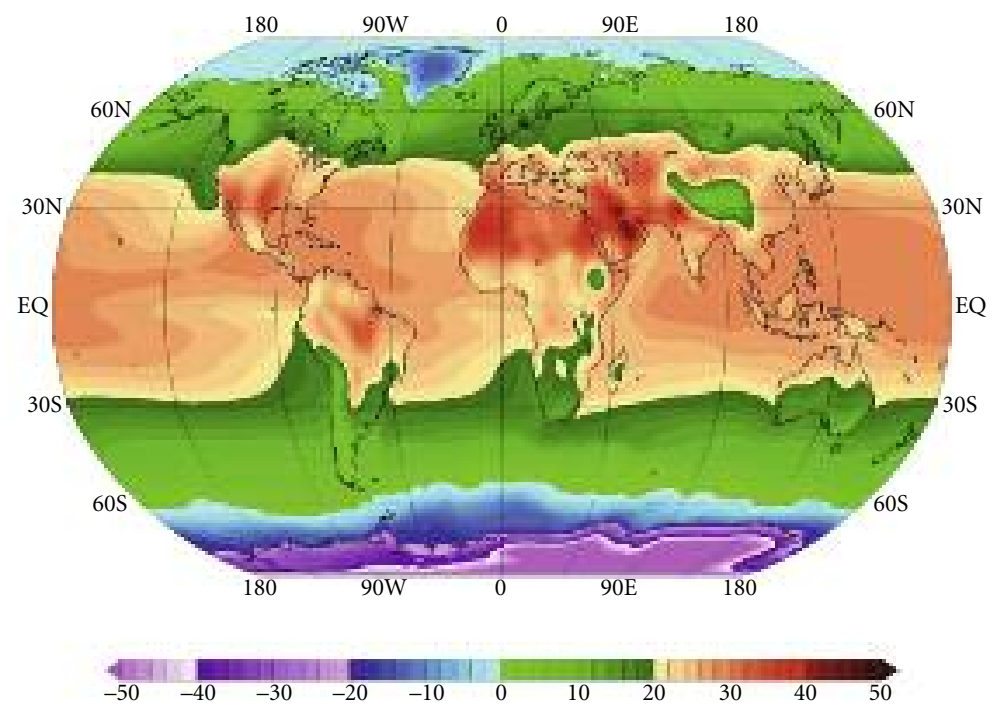

Figure 13: Global distribution of surface average August air temperatures in G1.

Forecast mean surface temperature [C] AUG 1990

Drainage of the Caspian and the Aral lake
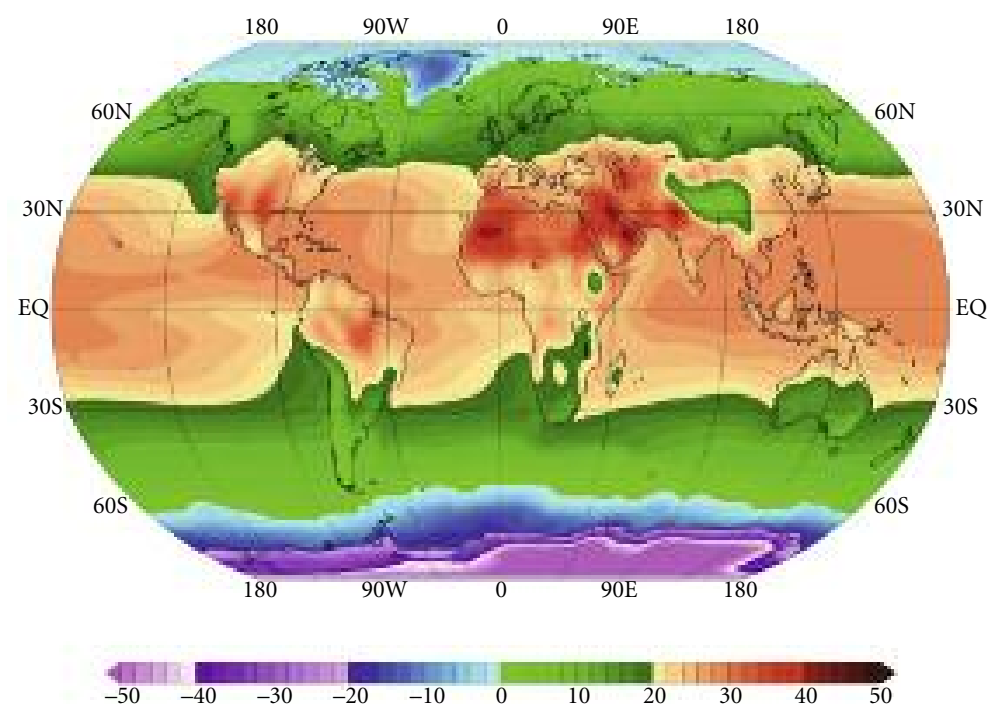

Figure 14: Global distribution of surface average August air temperatures in G2. 
Dahan A. 2010: Putting the Earth System in a numerical box? The evolution from climate modeling toward global change. Studies in history and philosophy of science B: studies in history and philosophy of modern physics 41-3. DOI: http://dx.doi.org/10.1016/j.shpsb.2010.08.002

Diamond, J. M. 2005: Collapse: how societies choose to fail or succeed. New York.

ERA40 reanalyse data 01/01/1989. Atmosphere database. European centre for medium range weather forecasts (ECMWF). Reading.

Gavrilov, M. B. 2005: Poplave i država. Vršačke vesti, 23. 5. 2005. Vršac.

Gavrilov, M. B., Jovanović, G. R., Janjić, Z. 2011: Sensitivity of a long-range numerical weather forecast model to small changes of model parameters. Advances in science and research 6. DOI: http://dx.doi.org/ 10.5194/asr-6-13-2011

Goosse, H., Barriat, P. Y., Lefebvre, W., Loutre, M. F., Zunz, V. 2013: Introduction to climate dynamics and climate modeling. Internet: http://www.climate.be/textbook (19.2.2013).

Hansen, J. E., Sato, M. 2012: Paleoclimate implications for human-made climate change. Climate Change: Inferences from paleoclimate and regional aspects. DOI: http://dx.doi.org/10.1007/978-3-7091-0973-1_2

Hagemann, S., Dümenil, L. 1996: Development of a parameterization of lateral discharge for the global scale. MPI Report 219. Hamburg.

Hagemann, S., Dümenil, L. 1998: A parameterization of the lateral waterflow for the global scale. Climate dynamics 14-1. DOI: http://dx.doi.org/10.1007/s003820050205

Hagemann, S., Arpe, K., Roeckner, E. 2006: Evaluation of the hydrological cycle in the ECHAM5 model. Journal of climate 19. DOI: http://dx.doi.org/10.1175/JCLI3831.1

Hagemann, S. 2002: An improved land surface parameter dataset for global and regional climate models. MPI Report 336. Hamburg.

Hamon, N., Sepulchere, P., Lefebvre, V., Ramstain, G. 2013: The role of eastern Tethys seaway closure in the Middle Miocene climatic transition (ca. 14Ma). Climate of the past 9. DOI: http://dx.doi.org/10.5194/ cp-9-2687-2013

Internet 1: http://celebrating200years.noaa.gov/breakthroughs/climate_model/AtmosphericModelSchematic.png (19.2.2013).

Kislov, A., Panin, A., Toropov, P. 2012. Paleostages of the Caspian Sea as a regional benchmark tests for the evaluation of climate model simulations. Climate of the past discussions 8. DOI: http://dx.doi.org/ 10.5194/cpd-8-5053-2012

Micklin, P. 2007. The Aral Sea disaster. annual review of earth and planetary sciences 35. DOI: http://dx.doi.org/ 10.1146/annurev.earth.35.031306.140120

Micklin, P., Aladin, N. V. 2008: Reclaiming the Aral Sea. Scientific American 298-4. Internet: http://www.sciam.com/ article.cfm?id=reclaiming-the-aral-sea\&sc $=$ rss (19.2.2013).

Murphy, L. N., Kirk-Davidoff, D. B., Mahowald, N., Otto-Bliesner, B. L. 2009: A numerical study of the climate response to lowered Mediterranean Sea level during the Messinian Salinity Crisis. Palaeogeography, palaeoclimatology, palaeoecology 279. DOI: http://dx.doi.org/10.1016/j.palaeo.2009.04.016

Peneva, E. L., Stanev, E. V., Stanychi, S. V., Salokhiddinov, A., Stulina, G. 2004. The recent evolution of the Aral Sea level and water properties: analysis of satellite, gauge and hydrometeorological data. Journal of marine systems 47, 1-4. DOI: http://dx.doi.org/10.1016/j.jmarsys.2003.12.005

Ramstain, G., Fluteau, F., Besse, J., Joussaume, S. 1997: Effect of orogeny, plate motion and land-sea distribution on Eurasian climate change over the past 30 million years. Nature 386. DOI: http://dx.doi.org/ $10.1038 / 386788 \mathrm{a} 0$

Roeckner, E., Bäuml, G., Bonaventura, L., Brokopf, R., Esch, M., Giorgetta, M., Hagemann, S., Kirchner, I., Kornblueh, L., Manzini, E., Rhodin, A., Schlese, U., Schulzweida, U., Tompkins, A. 2003: The atmospheric general circulation model ECHAM5 - model description 1. Report 349. Hamburg.

Roeckner, E., Brokopf, R., Esch, M., Giorgetta, M., Hagemann, S., Kornblueh, L., Manzini, E., Schlese, U., Schulzweida, U. 2004: The atmospheric general circulation model ECHAM5, sensitivity of simulated climate to horizontal and vertical resolution 2 II. Report 354. Hamburg.

Simmons, A. J., Burridge, D. M., Jarraud, M., Girard, C., Wergen, W. 1989: The ECMWF medium-range prediction models development of the numerical formulations and the impact of increased resolution. Meteorology and atmospheric physics 40, 1-3. DOI: http://dx.doi.org/10.1007/BF01027467

Singh, A., Seitz, F., Schwatke, C. 2012: Inter-annual water storage changes in the Aral Sea from multi-mission satellite altimetry, optical remote sensing, and GRACE satellite gravimetry. Remote sensing of environment 123. DOI: http://dx.doi.org/10.1016/j.rse.2012.01.001 
Toman, M. J. 2013: Aralsko jezero - simbolj okoljske katastrofe. Proteus 75, 9-10.

Tudryn, A., Chalié, F., Lavrushin, Yu. A., Antipov, M. P., Spiridonova, E. A., Lavrushin, V., Tucholka, P., Leroy, S. A. G. 2013: Late Quaternary Caspian Sea environment: Late Khazarian and Early Khvalynian transgressions from the lower reaches of the Volga River. Quaternary international 292. DOI: http://dx.doi.org/ 10.1016/j.quaint.2012.10.032

Varuschenko, S. I., Varuschenko, A. N., Klige, R. K. 1987: Changes in the regime of the Caspian Sea and non-terminal water bodies in paleotime. Moscow.

Wiin-Nielsen A. 1978: On balance requirements as initial conditions. European centre for medium range weather forecasts (ECMWF) report 9. Berkshire.

Vrišer, I. 1953: Padanje gladina Kaspijskega morja. Proteus 15-9. 